\title{
Rural women and poverty: A study on the role of RDRS for poverty alleviation in Bangladesh
}

\author{
M.M. Islam ${ }^{1}$, R.N. Ali ${ }^{2}$, M.M. Salehin ${ }^{2}$ and A.H.M.S. Islam ${ }^{3}$ \\ ${ }^{1}$ Department of Agricultural Extension Education and Rural Sociology, Sylhet Agricultural University, \\ ${ }^{2}$ Department of Rural Sociology and ${ }^{3}$ Department of Agricultural Economics, Bangladesh Agricultural \\ University, Mymensingh-2202
}

\begin{abstract}
No development objectives can be achieved without making women self reliant. The present study deals with the role of Rangpur Dinajpur Rural Service (RDRS) on poverty alleviation and women empowerment in Kaligonj upazila under Lalminirhat district considering their participation in different programmes of RDRS. The impact of the study was assessed in terms of economic and social gains accrued by the women's and their families' activities. The random sampling technique was used for selection of sample size. The test of mean difference, head count ratio, poverty gap, economic status index, social status index and decision-making index were used towards poverty alleviation and for women empowerment. The poverty situations improved as compared with that of the national level. It was clearly evident that participation in RDRS micro credit programmes, has substantially improved the respondent's economic condition, social condition and living standards. It referred the positive change in women empowerment in the study areas. By and large the women are better at present in respect of social awareness, freedom of attitude, financial freedom and exercising the right in decision making activities compared to their previous situation. It may, therefore, be inferred that the holistic approach followed by the RDRS for socioeconomic development led to increased family income, socioeconomic and decision making status in general and those of the women in particular in the study area.
\end{abstract}

Keywords: Rural Women, Women empowerment, Poverty alleviation, RDRS

\section{Introduction}

Bangladesh is a developing country. The overall male-female ratio is 105.4:100 (GOB, 2006). In this country with 42.1 percent population live below the recommended calorie intake of $2122 \mathrm{cal} /$ day (upper poverty line) and 25.5 percent below lower poverty line of 1805 $\mathrm{cal} /$ day/person. About 20 percent people are hardcore/ ultra poor and they face severe food insecurity every year. This section of people cannot take adequate food everyday for their active and healthy lives. The incidence of poverty in Bangladesh is alarming. Among the 177 countries of the world, the position of Bangladesh is 137 in terms of human development index (UNDP, 2006). The recent estimate of the 'head count' ratio is 23 percent for Pakistan, 27 percent for Srilanka and 35 percent for India. The head count ratio of poverty in Bangladesh is estimated at 43 percent for 1988-89 (Salahuddin and Shamim, 1996).

On the other hand, traditionally Bangladesh is a patriarchal country. In this male dominated society, man is the head of the family and he has full freedom to do anything. Usually women have less independence, "her father has authority over the childhood, her husband has authority over the youth and in the old age her son has authority over her." In this circumstances women obviously led a seclude life indoor. Confined to home women are assigned to duties of performing domestic chores, bearing and rearing children and serving to the husband and the elders (Islam, 2000).

Poverty is not only a state of deprivation, but also a state of vulnerability. For the female who constitutes half of the population, vulnerability is perhaps, even more central dimension of the poverty experience. Women now comprise the largest part of those living below the poverty lines, who are some 41 percent of the population (World Bank, 1990). 
The RDRS is the institution to break through with a view to bringing women population out of non-remunerative household activities and to participate in other more remunerative jobs to make them conscious about their social status in the family as well as in the country. Along with microcredit programmes the RDRS helps the rural housewives with providing skill training and popularizing modern life style, which would ultimately make them fit to adopt various income generating activities. RDRS has developed a number of sectional programmes which are facilitated by its credit, training and technical support services and are implemented through the overall Rural Development Programme (RDP). The important sectional programmes are livestock rearing, poultry rearing, fisheries, petty trading, vegetable selling, tailoring, rickshaw/van pulling, business and vegetable programmes. These programmes are generally designed to contribute positively to household activities and household decision making, utilization, management and conservation of natural resources for sustainable rural community development to remove poverty (RDRS, 2006). Thus, the study has been undertaken to know the impact of RDRS credit on its women beneficiaries in their different aspects of poverty and woman empowerment in the Kaligonj upazila of Lalmonirhat district of Bangladesh.

\section{Materials and Methods}

Five villages namely- Uttar Batrish Hazari, Latabor, Balapara, Paglarhat and Chaklarhat under Lalmonirhat district were selected for the study. After selection of the study area, a list of current beneficiaries (2005-2006) was collected from the RDRS branch offices at Chaparhat and Chaklarhat. A random sampling technique was followed in this study. Proportionally 20 percent respondents from the total population selected as sample. Total 60 loanees were selected from five villages of the study area in January, 2007 (Table 1). From 60 respondents data were collected of their present status (after membership) and the previous status (before membership).

Table 1. Distribution of the respondents from villages under study

\begin{tabular}{|l|c|c|}
\hline Name of village & Total no. of population & Number of sample \\
\hline Uttar Batrish Hazari & 76 & 15 \\
\hline Latabor & 60 & 12 \\
\hline Balapara & 55 & 11 \\
\hline Paglarhat & 45 & 9 \\
\hline Chaklarhat & 66 & 13 \\
\hline Total & 302 & 60 \\
\hline
\end{tabular}

After completion of pre-tabulation tasks, the tabular method was followed in some cases because it is simple in calculation, widely used and easy to understand. Mathematical and statistical techniques such as Head count Ratio, Poverty Gap, Economic Status Index, Social Status Index and Decision Making Index were used according to the following formulae to test variables used in this study.

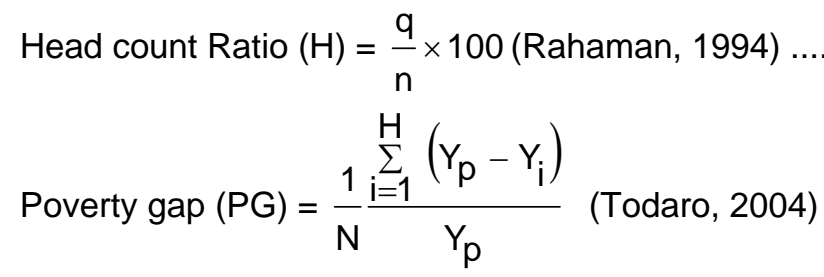

Economic status Index $(E S I)=\sum \frac{\text { Wifi }}{m} \times 100($ Sultana, 1998)

Social Status Index $($ SSI $)=\sum \frac{\text { Wifi }}{m} \times 100($ Sultana, 1998) 


\section{Results and Discussion}

\section{Demographic Characteristics of the Respondents}

Demographic characteristics are very important for social study. Sixty households from five villages were included in the present study. Most of the respondents (41.67\%) were in the age between 28-37 years. Table 2 shows that among the total respondents, 46.67 per cent of the respondents were in the membership up-to 5 years of RDRS. The Table also shows that 20.00 percent of the respondents are illiterate and 41.67 percent respondent's main occupation was housewife. Average Land sizes of the respondents households was 93.15 decimal.

Table 2 shows that average size of family is 5.3 persons. The Table shows that 32.07 percent of the population was children (of age below 14 years). This was less than the national average of 40.65 percent (BBS, 2004). Here, it may be noted that the lower percentages of children indicate the lower dependency ratio. The rest was between adult male (35.22) and adult female (32.70).

Table 2. Demographic Characteristics of the Respondents

\begin{tabular}{|l|c|c|}
\hline Demographic Characteristics & Number (N=60) & Percentages \\
\hline Age (28-37 years) & 25 & 41.67 \\
\hline Length of membership (Up to 5 years) & 28 & 26.67 \\
\hline Illiterate & 12 & 41.67 \\
\hline House wife (Main occupation) & 25 & 35.22 \\
\hline Adult male member & 112 & 32.70 \\
\hline Adult female member & 104 & 32.07 \\
\hline Children & 102 & 100 \\
\hline Total member & 318 & \\
\hline Average Land Sizes (decimal) & & 93.15 \\
\hline
\end{tabular}

Source: Field Survey, 2007

\section{Impact on Poverty and Women Empowerment}

\section{Poverty Situation of Respondents' Household}

To assess the economic impact of RDRS, overall poverty situation of participants was measured so that the economic change of the participants' households could be examined. Table 3 shows the poverty situation through the co-efficient likes head count ratio and poverty gap. The Table reveals that about 41.67 and 60 percent of the respondents were below the lower and upper poverty line in 1996 (before membership) but it was 26.67 and 45 percent in 2006 (after membership) respectively. The head-count ratio revealed that about 48.43 and 63.33 percent for lower and upper poverty line in 1996 respectively but it was 30 and 50 percent respectively in 2006. The head-count ratio of the national level in 2006 was 35.6 and 52.3 percent for lower and upper poverty line respectively. So, it observed that the percentage of below poverty line population was lower than that of the national level which indicated an improvement of poverty situation among the respondents' households after joining as a member of RDRS.

The poverty gap indicated that the mean shortfall in income of individual of the entire households. In the present study, the poverty gaps of selected population of the respondents' households were 11.02 and 19.27 percent for lower and upper poverty line in 1996 respectively but it was 5.6 and 9.33 percent respectively in 2006. Whereas the poverty gaps of national level in 2006 was 6.5 and 12 percent for lower and upper poverty line respectively. These gaps were lower than that of national level. The before and after poverty situation of the respondents are shown in Figs. 1 and 2. 
Table 3. Poverty Situation of Respondents' Household

\begin{tabular}{|l|c|c|c|c|c|c|}
\hline Year & $\begin{array}{c}\text { No. of respondent } \\
\text { below lower } \\
\text { poverty line }\end{array}$ & $\begin{array}{c}\text { Head- } \\
\text { Count } \\
\text { Ratio }\end{array}$ & $\begin{array}{c}\text { Poverty Gap } \\
\text { (PG) (in } \\
\text { percent) }\end{array}$ & $\begin{array}{c}\text { No. of respondent } \\
\text { below upper } \\
\text { poverty line }\end{array}$ & $\begin{array}{c}\text { Head- } \\
\text { Count } \\
\text { Ratio }\end{array}$ & $\begin{array}{c}\text { Poverty Gap } \\
\text { (GP) (in } \\
\text { percent }\end{array}$ \\
\hline 1996 (before membership) & $25(41.67)$ & 48.43 & 11.02 & $36(60)$ & 63.33 & 19.27 \\
\hline 2006 (after membership) & $16(26.67)$ & 30 & 5.6 & $27(45)$ & 50 & 9.33 \\
\hline
\end{tabular}

Source: Filed Survey, 2007

Finally, it was found that poverty situation is improved as compared with that of the national level (HES,. 1997, 2003, 2006).

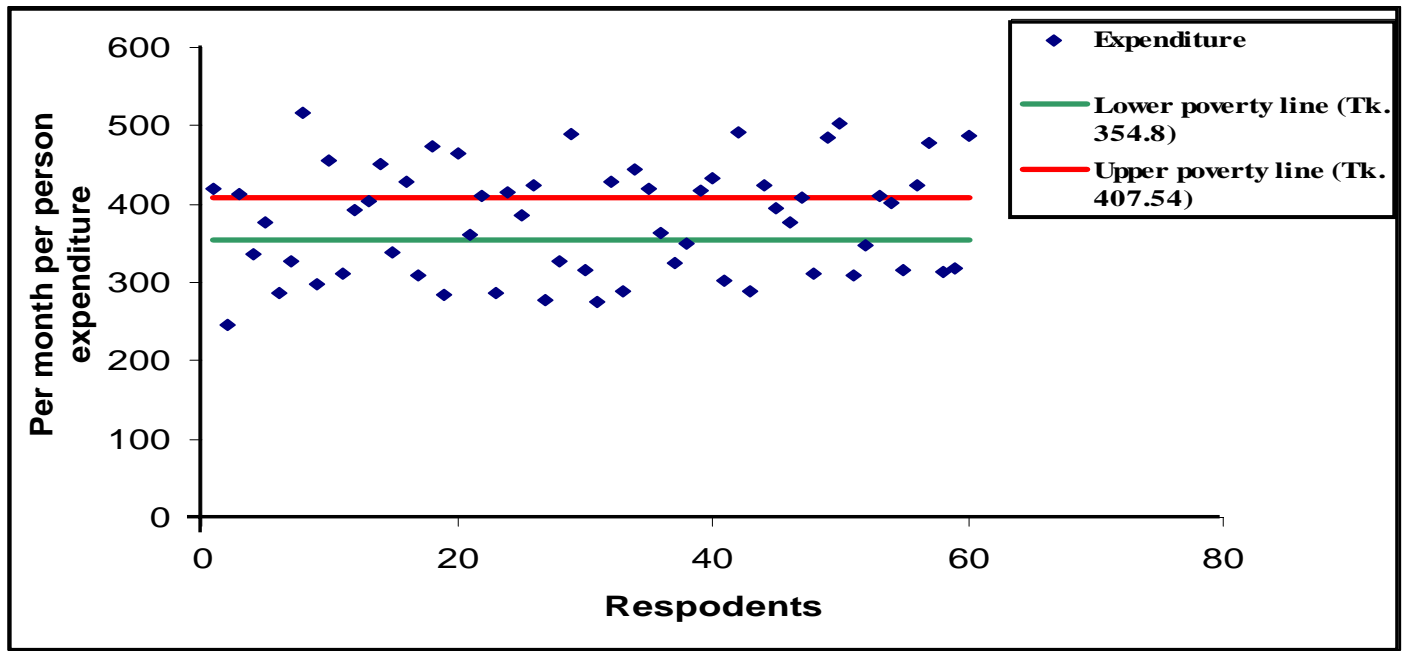

Fig. 1. Poverty Situation of Respondents' Household (Before)

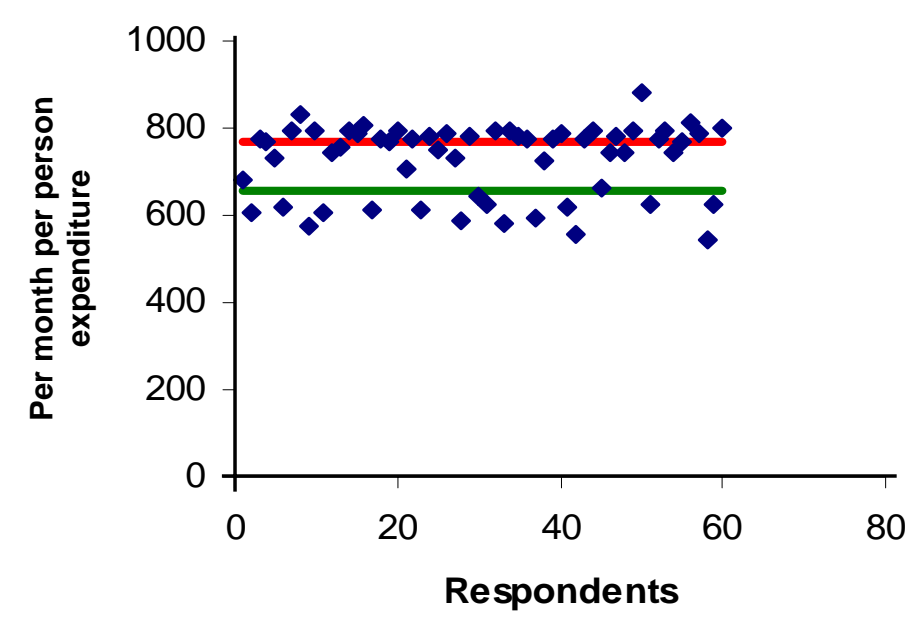

- Expenditure

Lower poverty line (Tk. 655.90)

Upper poverty line (Tk.766.48)

Islam et al.

Fig. 2. Poverty Situation of Respondents' Household (After) 


\section{Economic Status Index of Respondents' Households}

Table 4 indicates the economic status index of respondents. It is a modern approach to translate qualitative change in quantitative terms. It was hypothesized that the participation of women in RDRS would enable them to be employed with various incomes generating activities. As a consequence, the economic condition was sure to improve.

Table 4. Economic Status Index of the Respondents Household

\begin{tabular}{|l|c|c|c|c|}
\hline Types of economic status & Weight & $\begin{array}{c}\text { No. of } \\
\text { respondents }\end{array}$ & $\begin{array}{c}\text { Percentage of } \\
\text { respondents }\end{array}$ & $\begin{array}{c}\text { Index of economic } \\
\text { status }\end{array}$ \\
\hline No change & 0 & 4 & 6.67 & \multirow{2}{*}{$52.50 \%$} \\
\hline Little change & 1 & 13 & 21.67 & \multirow{2}{*}{} \\
\hline Medium change & 2 & 22 & 36.66 & 25 \\
\hline High change & 3 & 15 & 10 & \\
\hline Very high change & 4 & 6 & 100 & \\
\hline Total & - & 60 & & \\
\hline
\end{tabular}

Source: Field Survey, 2007

The economic status index expressed the improvement in households' economic conditions. The Table shows that improvement in the index of economic status was estimated at 52.50 percent. It is clearly evident that as a result of the participation of rural poor women in RDRS their economic condition has been improved substantially.

\section{Impact of RDRS on Social Status}

Findings related to social status are presented in Table 5. The Table shows that social status after involvement in the RDRS rose very highly in about 12 percent of respondents' households. Twenty three percent of respondents' households had high change of their social status. In about 42 percent of the households the change was medium. Twenty three percent had minor change. The value of weighted average index suggested that the respondents' households gained improvement in this social status by 55 percent.

Table 5. Social Status Index of the Respondents Household

\begin{tabular}{|l|c|c|c|c|}
\hline Types of Social Status & Weight & No. of respondents & $\begin{array}{c}\text { Percentage of } \\
\text { respondents }\end{array}$ & $\begin{array}{c}\text { Index of Social } \\
\text { status }\end{array}$ \\
\hline No change & 0 & 2 & 3.33 & \multirow{2}{*}{5} \\
\hline Little change & 1 & 12 & 20 & \multirow{2}{*}{$55 \%$} \\
\hline Medium change & 2 & 25 & 41.67 & \\
\hline High change & 3 & 14 & 23.33 & 11.67 \\
\hline Very high change & 4 & 7 & 100.00 & \\
\hline Total & - & 60 & & \\
\hline
\end{tabular}

Source: Field Survey, 2007

Hence, it could be said that RDRS made a considerable improvement on the social status of the poor women members in the study areas. Social status index was calculated in Appendix Table 4.

Decision- making power of women is an important indicator for assessing empowerment of women. This would be evident form Table 6 and Table 7. The design technique was a qualitative one to assess the empowerment of women after their participation in the RDRS. Table 6 shows the indices of the respondents on different decision-making items. 


\section{Impact on Decision Making Power}

It was evident from the Table that the decision making indices of participants increased tremendously on issues of education of sons and daughters, family health care and treatment, adopting family planning measures, business, receiving loan, repaying loan, use of loan, purchase input, participating in social ceremony, mobility, using parda, choosing own profession, guest invitation and entertainment, homestead production, repairing of house, marriage of son and daughter, family expenditure, involvement with cooperative or NGO, vaccination of children, casting vote etc. The decision making power was lowest in each items before participation in the RDRS. These referred the positive change in women empowerment in the study areas.

\section{Table 6. Decision-Making Status of Respondents}

\begin{tabular}{|l|c|c|c|c|c|c|c|c|}
\hline \multirow{2}{*}{ Items of decision making power } & \multicolumn{3}{|c|}{ Before membership } & \multicolumn{3}{c|}{ After membership } \\
\cline { 2 - 9 } & $\begin{array}{c}\text { Wife } \\
\text { alone }\end{array}$ & $\begin{array}{c}\text { Husband } \\
\text { alone }\end{array}$ & Both & DMI & $\begin{array}{c}\text { Wife } \\
\text { alone }\end{array}$ & $\begin{array}{c}\text { Husband } \\
\text { alone }\end{array}$ & Both & DMI \\
\hline Education of sons and daughters & 0 & 24 & 18 & 0.30 & 4 & 8 & 41 & 0.925 \\
\hline Family health care and treatment & 2 & 35 & 23 & 0.45 & 8 & 9 & 43 & 0.983 \\
\hline Family planning & 1 & 28 & 24 & 0.491 & 9 & 15 & 36 & 0.90 \\
\hline Business & 0 & 27 & 7 & 0.201 & 3 & 22 & 9 & 0.441 \\
\hline Loan received & 2 & 49 & 9 & 0.217 & 6 & 9 & 45 & 0.95 \\
\hline Loan repayment & 2 & 49 & 9 & 0.217 & 6 & 9 & 45 & 0.95 \\
\hline Use of loan & 2 & 49 & 9 & 0.217 & 7 & 15 & 38 & 0.867 \\
\hline Purchase goods & 1 & 48 & 11 & 0.20 & 5 & 17 & 38 & 0.80 \\
\hline Participation in society & 0 & 37 & 23 & 0.383 & 11 & 9 & 40 & 1.033 \\
\hline Going alone out side & 2 & 35 & 23 & 0.45 & 21 & 11 & 28 & 1.167 \\
\hline Main facing & 2 & 32 & 26 & 0.50 & 26 & 5 & 29 & 1.35 \\
\hline Choosing own profession & 1 & 38 & 21 & 0.383 & 21 & 6 & 33 & 1.25 \\
\hline Guest invitation and entertainment & 4 & 33 & 23 & 0.517 & 13 & 15 & 32 & 0.967 \\
\hline Homestead production & 1 & 42 & 17 & 0.317 & 8 & 19 & 33 & 0.817 \\
\hline Repairing the house & 0 & 51 & 9 & 0.15 & 4 & 36 & 20 & 0.467 \\
\hline Marriage of sons and daughters & 0 & 22 & 13 & 0.217 & 1 & 8 & 32 & 0.683 \\
\hline Family expenditure & 0 & 52 & 8 & 0.133 & 5 & 10 & 45 & 0.917 \\
\hline Involvement with cooperative \\
NGO
\end{tabular}

Source: Field Survey, 2007 (Sultana, 1998)

Table 7. Decision Making Index of the Respondents

\begin{tabular}{|l|c|}
\hline Items & Value \\
\hline Total decision making Indices (before) & 6.86 \\
\hline Total decision making Indices (after) & 18.584 \\
\hline Average decision making Indices (before) & 0.343 \\
\hline Average decision making Indices (after) & 0.929 \\
\hline Average increase & 0.586 \\
\hline Increase rate (\%) & $58.60 \%$ \\
\hline
\end{tabular}

Table 7 reveals that overall women's decision making power increased by a substantial percentage (58.60\%). It increased most in using parda (1.35), casting vote (1.35), and lowest in business (0.441), repairing of house (0.467).

Islam et al. 


\section{Conclusion}

The study was conducted to assess the impact of the training and credit programmes of the women participants. The women under the RDRS in the study areas tried to improve their socioeconomic status by utilizing credit and training in different income generating activities. They achieved a substantial achievement in their livelihood and poverty situation. Therefore, the poverty situations, livelihoods patterns and women empowerment condition improved among the respondents' households. The livelihoods pattern and poverty situation of women is constrained by a number of factors.

\section{References}

BBS 2004. Statistical Year Book of Bangladesh, Bangladesh Bureau of Statistics, Statistics Division, Ministry of Planning, Government of the People's Republic of Bangladesh, Dhaka, Bangladesh

GOB 2006. Bangladesh Economic Review, Economic Division, Ministry of Finance, Government of the People's Republic of Bangladesh, Dhaka.

HES 1997. Household Expenditure Survey 1995-1996, Bangladesh Bureau of Statistics, Statistics Division, Ministry of Planning, Government of the People's Republic of Bangladesh, Dhaka, Bangladesh.

HES 2003. Household Income and Expenditure Survey, Bangladesh Bureau of Statistics, Statistics Division, Ministry of Planning, Government of the People's Republic of Bangladesh, Dhaka, Bangladesh.

HES 2006. Preliminary Report on Household Income and Expenditure Survey- 2005, Bangladesh Bureau of Statistics, Statistics Division, Ministry of Planning, Government of the People's Republic of Bangladesh, Dhaka, Bangladesh.

Islam, M. 2000. "Women Look Forward". pp; 3-34 in: M. Ahamed (Ed) Bangladesh in New Millium. CDL. Dhaka.

Nath, N.C. 1990. Rural Development: 12-A Base Line Study. Bangladesh Institute of Development Studies, E-17, Agargaon, Sher- E- Bangla Nagar, Dhaka.

Rahman, P.M.M. 1994. Poverty Issue in Rural Bangladesh. The University Press Limited, Dhaka, Bangladesh.

RDRS 2006. Annual Report, Rangpur Dinajpur Rural Service(RDRS) Dhaka, Bangladesh.

Salahuddin, K. and Shamim, I. 1996 Rural Women in Poverty: NGO Interventions for poverty, Women for Women, 63/2 Laboratory Road Dhaka.

Sultana, T. 1998. Impact of Development Programme on Economic and Social Status of Rural Women: A Study of CVDP in Selected Areas of Comilla District. Unpublished M.S Thesis, Bangladesh Agricultural University, Mymensingh.

Todaro, M.P. and Smith, S.C. 2004. Economic Development, Pearson Education (Singapur) Pte, Ltd. ( $8^{\text {th }}$ ed) Indian Branch, New Delhi.

UNDP 2006. UNDP Report on Human Development Index, United Nations Development Programmes, Dhaka, Bangladesh.

World Bank 1990. World Bank Development Report, Washington, D. C. 